\title{
Preparation and Electrochemical Properties of Gadolinium Oxide-doped Carbon Aerogels/Sulfur Composites
}

\author{
Anqiao Zheng ${ }^{1}$, Rui Liang ${ }^{2}$, Han Wu ${ }^{1}$, Guodong Jiang ${ }^{1,3}$, Mingxia Fan ${ }^{1,3}$, Jian Xiong ${ }^{1,3}$, \\ Songdong Yuan ${ }^{1,3, *}$ \\ ${ }^{1}$ Hubei Collaborative Innovation Center for High-efficiency Utilization of Solar Energy, Hubei \\ University of Technology, Wuhan 430068, China \\ ${ }^{2}$ Sunwoda Electronic Co.,Ltd, Shenzhen 518108, China \\ ${ }^{3}$ The Synergistic Innovation Center of Catalysis Materials of Hubei Province, Wuhan 430068, China

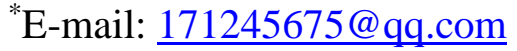

Received: 6 October 2021 / Accepted: 22 November 2021 / Published: 5 January 2022

\begin{abstract}
A carbon aerogel (CA) was successfully synthesized by a sol-gel method combined with freeze-drying, followed by solution permeation impregnation and high-temperature carbonization to obtain a gadolinium oxide $\left(\mathrm{Gd}_{2} \mathrm{O}_{3}\right)$-doped CA composite $\left(\mathrm{CA} @ \mathrm{Gd}_{2} \mathrm{O}_{3}\right)$. Then, CA@ $\mathrm{Gd}_{2} \mathrm{O}_{3}$ was incorporated with sulfur by the melt-diffusion method to obtain $\mathrm{CA} @ \mathrm{Gd}_{2} \mathrm{O}_{3} @ \mathrm{~S}$ composites, which exhibited a superior electrochemical performance. The initial discharge specific capacity of the composite reached $1168.4 \mathrm{mAh} / \mathrm{g}$ at $0.1 \mathrm{C}$ and maintained a reversible specific capacity of $814.4 \mathrm{mAh} / \mathrm{g}$ after 100 cycles. The outstanding electrochemical properties were mainly attributed to the strong polar adsorption of polysulfides by the abundant $\mathrm{O}^{2-}$ ions on the surface of $\mathrm{Gd}_{2} \mathrm{O}_{3}$, which inhibited the shuttle effect of polysulfides. Moreover, the $\mathrm{CA}$ doped with $\mathrm{Gd}_{2} \mathrm{O}_{3}$ maintained a high specific surface area and large pore capacity to alleviate the poor electrical conductivity and volume expansion effect of sulfur cathode materials.
\end{abstract}

Keywords: lithium-sulfur battery, carbon aerogel, $\mathrm{Gd}_{2} \mathrm{O}_{3}$, shuttle effect, cathode

\section{$\underline{\text { FULL TEXT }}$}

(C) 2022 The Authors. Published by ESG (www.electrochemsci.org). This article is an open access article distributed under the terms and conditions of the Creative Commons Attribution license (http://creativecommons.org/licenses/by/4.0/). 